Bolm Inst. oceanogr., S Paulo, $36(1 / 2): 1-16,1988$

\title{
O MICROFITOPLÂNCTON DAS ÁGUAS COSTEIRAS DO LITORAL FLUMINENSE (ESTADO DO RIO DE JANEIRO): LISTA DE ESPËCIES E ASPECTOS ECOLŌGICOS
}

\author{
Nadja M. LINS DA SILVA; Jean L. VALENTIN \& Christina T. B. BASTOS
}

Instituto de Estudos do Mar Almirante Paulo Moreira

(Rua Kioto, 253 - 28910 Arraial do Cabo, RJ)

\begin{abstract}
Phytoplankton of the coastal water between Cabo Frio and Rio de Janeiro were studied at the upwelling season (October, January and March). Qualitative and quantitative variations are analized in function of the hydrological conditions by means of a miltivariate statistical treatment of data. Cabo Frio upwelling is responsible for occurrence of a thermocline in the euphotic layer which induces phytoplankton growth, beginning by small-sized species (Nitzschia spp, Skeletonema costatuml and evoluting to highest diversity and quantity of different microphytoplanktonic forms (Guinardia, Rhizosolenia, Chaetoceros, Thalassiothrix). When water column is sharply stratified, we observe Guanabara Bay influence, with high growth of Skeletonema costatum and high quantity of detritus together with blue-green algae and nanoplanktonic forms.
\end{abstract}

Descriptors: Phytoplankton, Coastal waters, Coastal upwelling, Species diversity, Multivariate analysis, Ecological succession, Rio de Janeiro: Brazil. Descritores: Fitoplâncton, Águas costeiras, Ressurgência costeira, Diversidade das espécies, Anālise multivariada, Sucessão ecolögica, Rio de Janei ro.

\section{Introdução}

As āguas marinhas que banham o litoral fluminense entre Cabo Frio e Rio de Janeiro, fazem parte do ecossistema da ressurgência de Cabo Frio, recebendo forte influência da subida da Ägua Central do Atlântico Sul (ACAS). Essa influência é de natureza física (baixas temperaturas, freqüentemente inferiores a $15^{\circ} \mathrm{C}$ ), química (teores elevados de sais nutrientes) e biológica (transferência de populações, eutroficação).

As pesquisas sobre o microfitoplâncton até agora realizadas neste ecossistema abordaram principalmente os aspectos temporais numa estação fixa (Valentin et al., 1985), ou geográficos na plataforma continental (Valentin et al., 1987). Entretanto, existem evidências de que as maiores concentrações planctônicas ocorrem numa estreita faixa costeira entre Cabo Frio e Rio de Janeiro, área de intensa atividade pesqueira. Re-

Contr. n! 689 do Inst. oceanogr. da Usp. centes medições de correntes confirmaram a existência de uma componente normal à costa. Essa corrente seria provavelmente responsável pelo represamento do plâncton ao longo da costa.

Estudos anteriores sobre a hidrologia da região evidenciaram uma nítida contribuição de águas costeiras quando, por ventos SW, ocorre um processo de subsidência com descida da ACAS e invasão de água superficial quente de origem oceânica (Corrente do Brasil), ou continental (água de baixa salinidade oriunda, em parte, da Baía de Guanabara).

Este trabalho teve por objetivo analisar com maiores detalhes, a estrutura do microfitoplâncton desta área costeira sujeita a uma alternância de diversas massas d'água, sua composição específica e os fatores responsáveis pela sua variabilidade. Embora sabendo que, em regiões tropicais, as frações pico e nanoplanctônicas são as vezes responsáveis pelas maiores taxas de produção primária, nosso trabalho limitou-se ao compartimento microfitoplanctônico (células 
Bolm Inst. oceanogr., S Paulo, 36(1/2), 1988

de tamanho maior que $20 \mathrm{micra}$ ), onde foi possível se fazer um estudo sistemático que permitiu uma caracterização das condições hidrológicas através das comunidades de espécies.

Este trabalho constituiu parte de um programa de pesquisas hidrobiológicas do litoral fluminense, cujos resultados encontram-se no prelo (Andre et al.) ou já publicados (Valentin et al., 1987).

\section{Métodos}

As coletas d'água foram efetuadas com garrafa de Nansem nas profundidades de $0,5,15$ e 30 metros, em 10 estações costeiras situadas entre Cabo Frio e a Baía de Guanabara, na ocasião de três comissões do AvPqOc SO OLIVEIRA: dia 17/10/84 (operação PLATAFORMA IV, chamada PL4 no texto), dia 02/01/85 (operação PLATAFORMA V, ou PL5) e dia $27 / 03 / 85$ (operação PLATAFORMA VI ou PL6) (Fig. 1). As amostras de água $(250 \mathrm{ml})$ destinadas ao estudo do microfitoplâncton foram imediatamente fixadas a bordo com formol neutralizado a 4 porcento. Para identificação e contagem das células, empregou-se o método de sedimentação de Utermoh1 (1958) com cubetas de $50 \mathrm{ml}$ e um tempo de sedimentação de 48 horas. Foi utilizado o microscópio invertido marca Zeiss com aumento de 250 vezes. De maneira geral, foram contadas as células contidas em metade da câmara, exceto pa$\mathrm{ra}$ as espécies mais abundantes (mais de 100 células em um diâmetro da câmara) que foram contadas em apenas 2 diâmetros. Na identificação das espécies utilizou-se principalmente trabalhos de Cleve-Euler (1951, 1952, 1953 e 1955), Cupp (1943), Hendey (1964), Peragallo \& Peragallo (1965) e Steidinger \& Williams (1970).
As variáveis físico-químicas foram analisadas simultaneamente e os resultados publicados separadamente (Andre et al., no prelo).

Para facilitar a análise e a interpretação integrada dos dados reunidos, com intuito de definir os fatores ecológicos e seu impacto sobre as comunidades algais, fez-se necessário o uso de uma técnica estatística multivariada, a análise fatorial em componentes principais (ACP). A análise fatorial tem por objetivo simplificar e condensar a massa de dados iniciais, expressando a trama complexa de interrelações entre variáveis por um menor número de fatores. Além de evidenciar esses fatores, a análise fatorial facilita também uma definição das comunidades de espécies (Harmann, 1970). Os métodos multivariados são de uso freqüente em ecologia marinha, embora ainda pouco difundidos no Brasil, nesta ārea (Verdinelli, 1980; Valentin, 1981; Jacobi, 1987).

\section{Resultados}

\section{Condições hidrolōgicas}

As condições hidrológicas observadas durante as três comissões foram caracterizadas pela ocorrência do fenômeno da ressurgência com afloramento da ACAS (temperatura inferior a $18^{\circ} \mathrm{C}$ ) ou presença de termoclina, e a influência de água costeira (salinidade inferior a 35,20 ppm). 0 diagrama TS (Fig. 2) ilustra esses diversos tipos de água.

\section{Operação PLATAFORMA IV}

\section{Temperatura e salinidade}

Nesta comissão, as águas frias de ressurgência afloraram em toda a extensão do litoral com temperaturas inferiores a

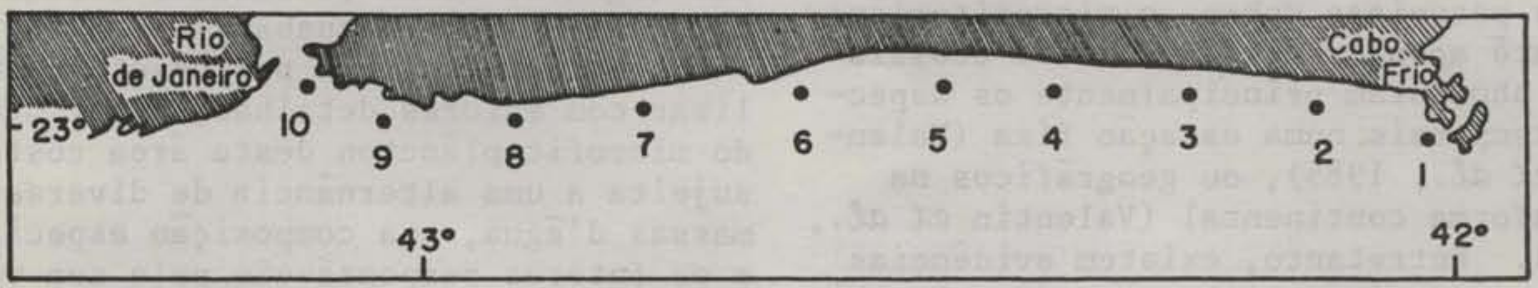

Fig. 1. Posição das estações de coleta das operações PLATAFORMA. 


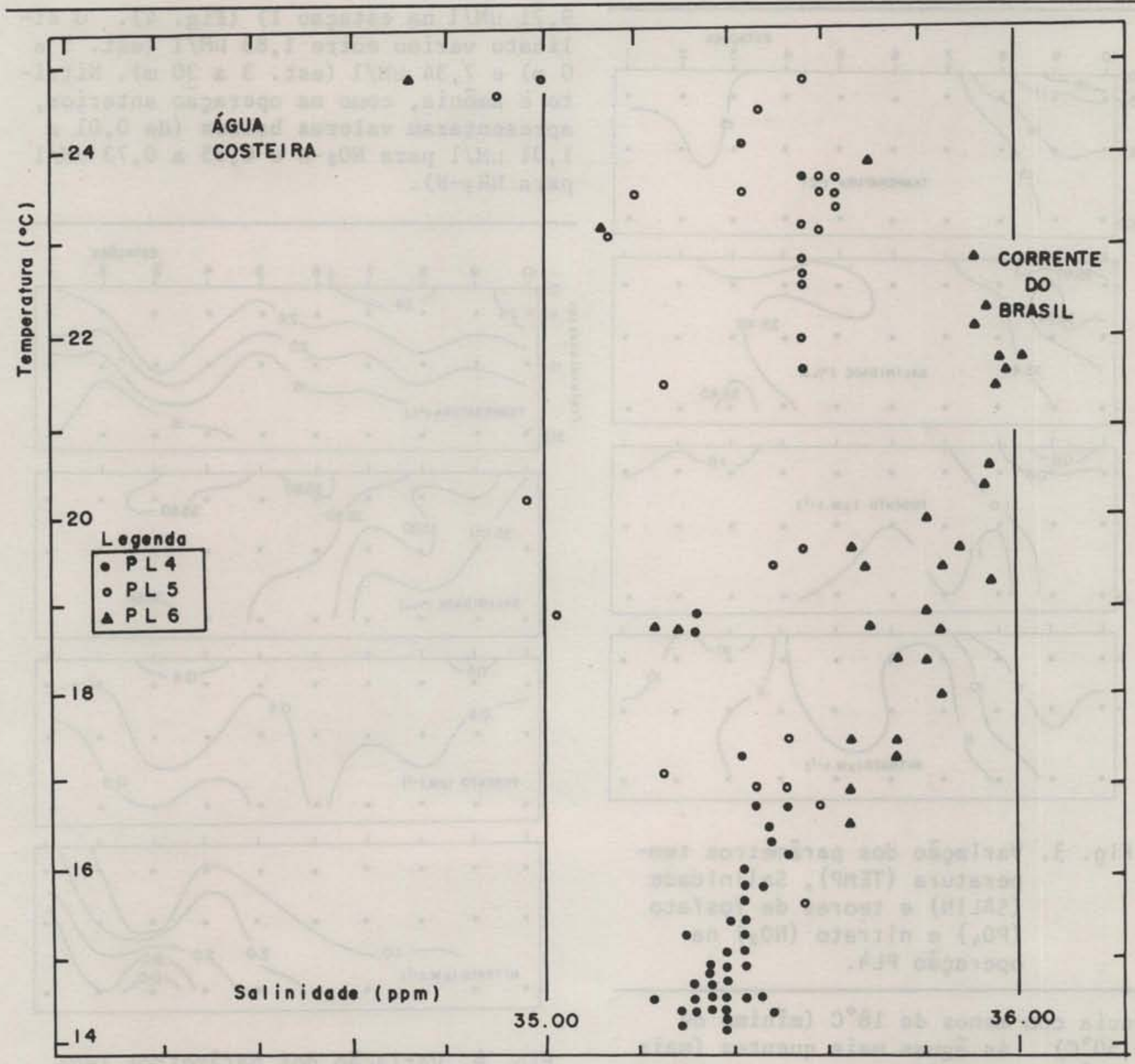

Fig. 2. Diagrama TS nas operações PL4, PL5 e PL6.

$18^{\circ} \mathrm{C}$ na superfície e inferiores a $15^{\circ} \mathrm{C}$ no fundo ( 30 metros), com exceção das estações 9 e 10 (próximas ao Rio de Janeiro) onde as águas mostraram um leve aquecimento na superfície $(18,5$ e $18,7^{\circ} \mathrm{C}$ ) mas permaneceram frias no fundo $\left(16,0\right.$ e $\left.15,4^{\circ} \mathrm{C}\right)$. A salinidade variou pouco nesta comissão (entre 35,30 e $35,50 \mathrm{ppm}$ ) (Fig. 3).

\section{Nutrientes}

De maneira geral, as āguas frias têm teores de fosfato entre 0,7 e $1,1 \mu \mathrm{M} / 1$ e de nitrato entre 9,0 e $12,0 \mu M / 1$. Nas águas de superfície próximas ao Rio de Janeiro (estações 8,9 e 10), os teores diminuiram respectivamente em $0,81,0,56$ e $0,60 \mu \mathrm{M} / 1$ para o fosfato e em 7,65 , 7,88 e $7,30 \mu \mathrm{M} / 1$ para o nitrato (Fig. 3 ). Os teores em nitrito e amônia foram baixos (inferiores a 0,3 e $0,6 \mu \mathrm{M} / 1$ respectivamente) e os de silicato seguiram o mesmo padrão de variação que o nitrato (de 6,0 a 7,0 $\mu \mathrm{M} / 1$ em água fria, de 4,0 a $6,0 \mu \mathrm{M} / 1$ nas estações 8 a 10$)$.

\section{Operação PLATAFORMA V}

\section{Temperatura e salinidade}

A estrutura hidrológica foi caracterizada pela presença de uma termoclina a cerca de $20 \mathrm{~m}$ de profundidade. Uma camada de água superficial quente $(18,0$ a $\left.24,8^{\circ} \mathrm{C}\right)$ se superpôs às águas de ressur- 


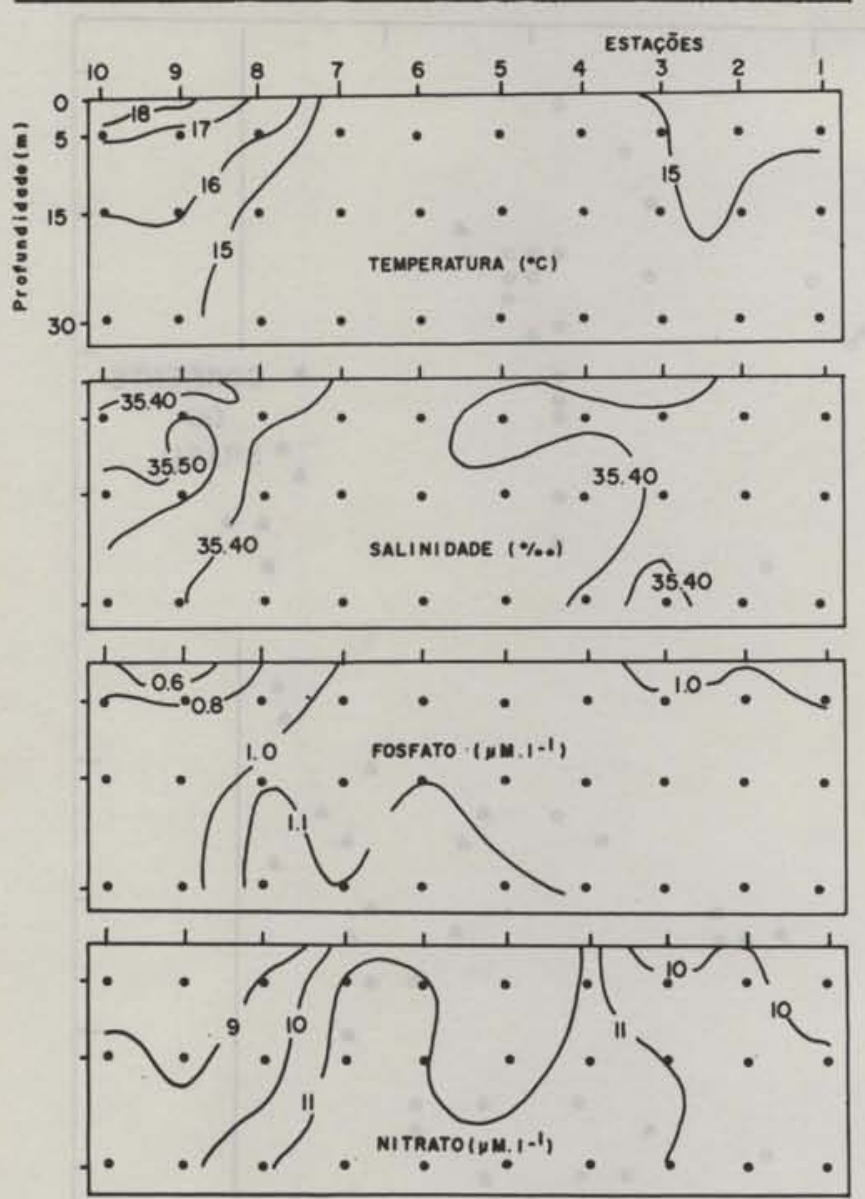

Fig. 3. Variação dos parâmetros temperatura (TEMP), Salinidade (SALIN) e teores de fosfato $\left(\mathrm{PO}_{4}\right)$ e nitrato $\left(\mathrm{NO}_{3}\right)$ na operação PL4.

gência com menos de $18^{\circ} \mathrm{C}$ (mínimo de $15,50^{\circ} \mathrm{C}$ ). As águas mais quentes (mais de $24^{\circ} \mathrm{C}$ ) se localizaram perto do Rio de Janeiro (estações 7 a 10), e as mais frias (entre 15,5 e $17,0^{\circ} \mathrm{C}$ ) nas profundidades de 15 a 30 metros das estações 1 a 3 , indicando uma maior subida da ACAS na ārea próxima a Cabo Frio. A salinidade variou entre 35,40 e $35,00 \mathrm{ppm}$ no trecho entre as estaçoes 1 e 7 , e diminuiu abaixo de $35,20 \mathrm{ppm}$ entre as estações 7 e 10 (Fig. 4)

\section{Nutrientes}

Os teores mais baixos de fosfato $(0,31$ e $0,51 \mu \mathrm{M} / 1$ ) foram registrados na superfície e os mais altos $(0,8$ e $1,00 \mu \mathrm{M} / 1)$, no fundo, perto de Cabo Frio. Os nitratos seguiram o mesmo padrão de variação, com valores mínimos na superfície, entre 0,08 (est. 10 e $2,15 \mu \mathrm{M} / 1$ (est. 1) e valores máximos no fundo, próximo a Cabo Frio (de 4,77 $\mu M / 1$ na estação 4, até
9,71 $\mu M / 1$ na estação 1) (Fig. 4). 0 silicato variou entre $1,83 \mu \mathrm{M} / 1$ (est. 5 a $0 \mathrm{~m}$ ) e $7,34 \mu \mathrm{M} / 1$ (est. 3 a $30 \mathrm{~m}$ ). Nitrito e amônia, como na operação anterior, apresentaram valores baixos (de 0,01 a $1,01 \mu \mathrm{M} / 1$ para $\mathrm{NO}_{2}-\mathrm{N}$ e 0,35 a $0,73 \mu \mathrm{M} / 1$ para $\mathrm{NH}_{3}-\mathrm{N}$ ).
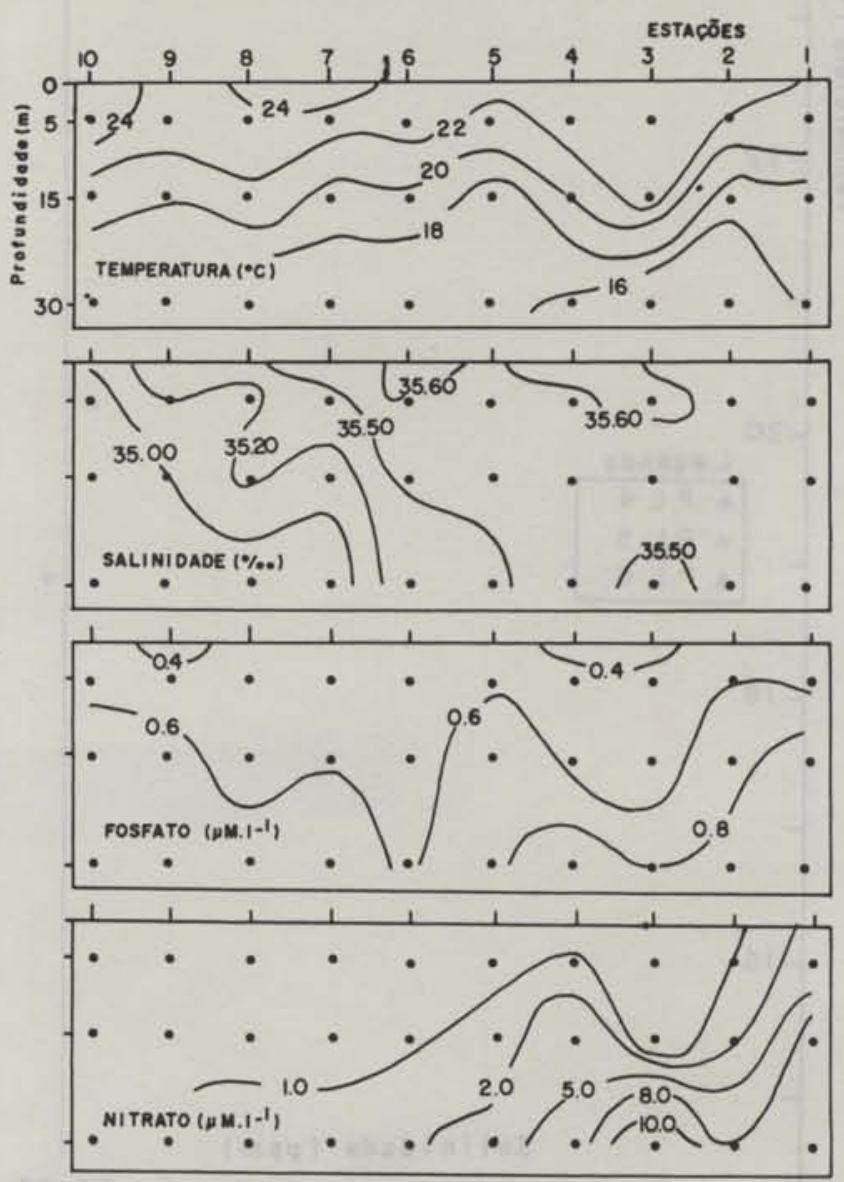

Fig. 4. Variação dos parâmetros temperatura (TEMP), Salinidade (SALIN) e teores de fosfato $\left(\mathrm{PO}_{4}\right)$ e nitrato $\left(\mathrm{NO}_{3}\right)$ na operação PL5.

\section{Operacão PLATAFORMA VI}

\section{Temperatura e salinidade}

A estrutura termo-halina observada nesta operação foi praticamente idêntica à anterior, com presença de uma termoclina abaixo de $15 \mathrm{~m}$ de profundidade. Na superfície, a temperatura variou entre $19,4^{\circ} \mathrm{C}$ (est. 1) e $25,22^{\circ} \mathrm{C}$ (est. 10). As temperaturas mais baixas (menos de $18^{\circ} \mathrm{C}$ ) foram registradas no fundo, com mínima de $16,4^{\circ} \mathrm{C}$ na estação 5 . O diagrama de salinidade evidencia um núcleo de água da Corrente do Brasil (salinidade de $36,00 \mathrm{ppm}$ ) a 5 metros na estação 4 , e a presença de água costeira (salinidade 
inferior a $35,20 \mathrm{ppm}$ ) com significativa participação de água continental entre as estaçoes 8 e 10 onde a salinidade diminuiu até $33,39 \mathrm{ppm}$ em superfície (Fig. 5).

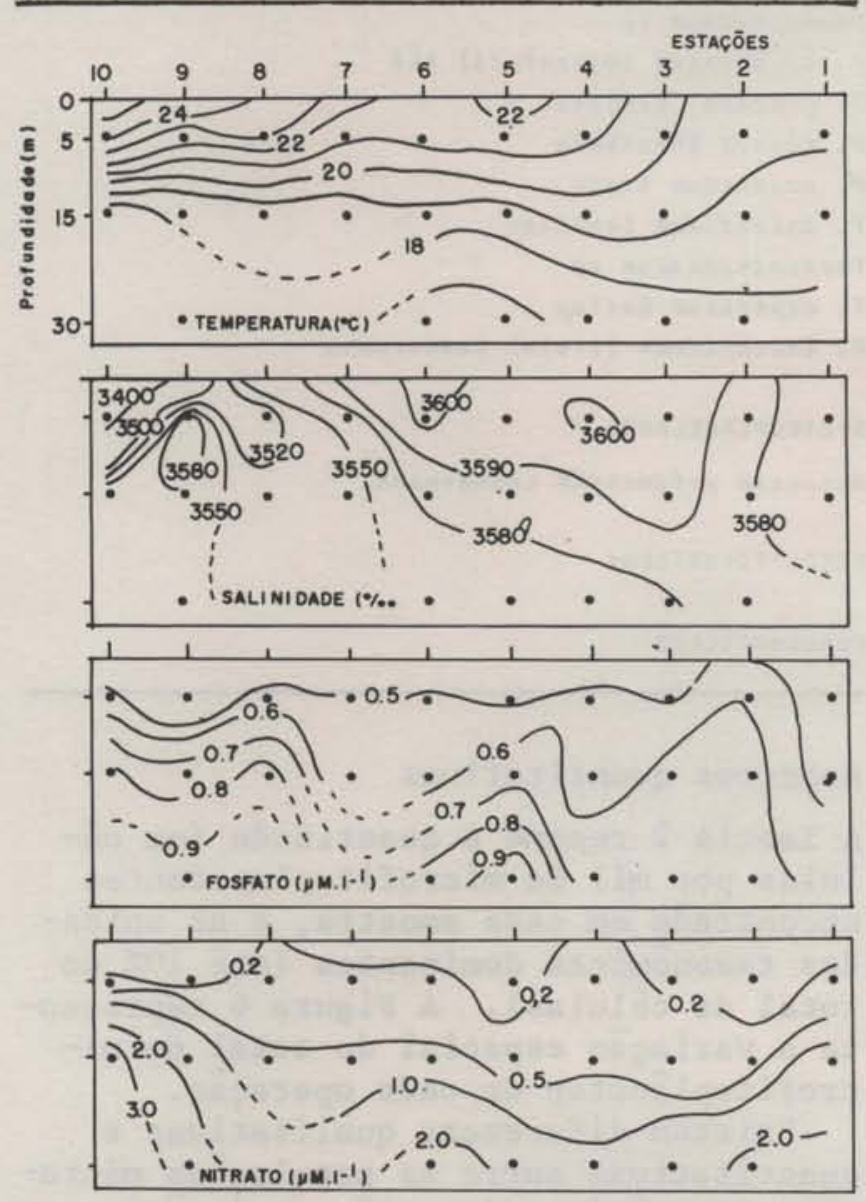

Fig. 5. Variação dos parâmetros temperatura (TEMP), Salinidade (SALIN) e teores de fosfato $\left(\mathrm{PO}_{4}\right)$ e nitrato $\left(\mathrm{NO}_{3}\right)$ na operação PL6.

\section{Nutrientes}

Os teores em fosfato variaram entre 0,40 e $0,96 \mu \mathrm{M} / 1$ e os de nitrato foram, na maioria, inferiores a $1,0 \mu \mathrm{M} / 1$, com valores máximos entre 1,0 e $3,07 \mu \mathrm{M} / 1$ abaixo de 15 metros (Fig. 5). 0 silicato foi também baixo, entre $1,73 \mu \mathrm{M} / 1$

(est. 7) e $5,59 \mu \mathrm{M} / 1$ (est. 5). Os teores em nitrito e amônia não ultrapassam $1,0 \mu \mathrm{M} / 1$.

\section{0 microfitoplâneton}

Aspectos qualitativos

A Tabela 1 apresenta o inventário das espécies do microfitoplâncton encontradas durante as três operações. Esta lista não é exaustiva. Dúvidas permanecem quanto à identificação de alguns taxons, para os quais foram colocados apenas os nomes de gênero, família e até classe de acordo com o caso.

Foram reperioriados 103 taxons, divididos em 78 diatomáceas, 21 dinoflagelados, 2 silicoflagelados; alguns cocolitoforídeos e euglenofíceas foram contados, mas não identificados. Mesmo levando em conta as indeterminações, as diatomáceas foram as mais diversificadas, sendo os gêneros mais representativos: Rhizosolenia (11 espécies e 2 formas), Chaetoceros ( 7 espécies e 3 variedades) e Nitzschia (6 espécies).

\section{Tabela 1. 0 microfitoplâncton das äguas} costeiras do litoral fluminense. Inventärio das espécies

\section{DIATOMACEAS}

Actinoptychus campanulifer A. Schmidt Amphora sp.

A. biggibba Grunow

Asterionella glacialis Castracane

Basteriastrum sp.

Cerataulina pelagica (Cleve) Hendey

Chaetoceros sp

C. compressus Lauder

C. curvisetus Cleve

C. decipiens cleve

C. didymus var, anglica (Grunow) Gran

C. didymus var. didymus Ehrenberg

c. didymus var. protuberans (Lauder) Gran and Yendo

c. Lorenzianus Grunow

C. pendulus Karsten

C. peruvianus Brightwell

climacodium frauenfeldianum Grunow

Cocconeis sp

Corethron criophilum Castracane

Coscinodiscus sp

Cyclotella sp

Dactyliosolen antarcticus Castracane

Detonula pumila (Castracane) Schutt

Diploneis sp

D. bombus Ehrenberg

D. didyma (Ehrenberg) Ehrenberg

Ditylum brightwelli ( $T$. West) Grunow

Eucampia connuta (Cleve) Grunow

Guinardia flaccida (Castracane) H'. Peragallo

Gyrosigma sp

Hemiaulus haucki Grunow

H. sinensis Greville

Leptocylindrus danicus cleve

L. minimus Gran

Licmophora sp 
Tabela 1. Cont.

Margaritum tenebro (Leuduger-Fortmorel) H. Moreira Melosira nummuloides (Dillwyn) Agardh

Navicula sp

$N$. membranacea $\mathrm{Cleve}$

N. pennata $5 \mathrm{chmidt}$

Nitzschia sp

N. angularis Wm. Smith

N. Closterium (Ehrenberg) Wm, Smith

$N$. delicatissima Cleve

$N$, panduriformis Gregory

N, sigma (Kutzing) Wm. Smith

N. spathulata (Wm. Smith) Brébisson

Paralia sulcata (Ehrenberg) Cleve

pleurosigma sp

$P$. naviculaceum Brëbisson

P. normani Ralfs

$P$. reversum Greo

Raphoneis amphyceros Ehrenberg

Rhizosolenia sp

$R$. alata $f$, alata (Brightwell)

$R$, alata $f$ gracillima ( $C l e v e$ ) Grunow

$R$. calcar-avis $M$. Schultz

$R$. delicatula $\mathrm{Cleve}$

$R$. Gragilissima Bergon

$R$. indica Peragallo

$R$. pungens 6 leve

$R$. robusta Norman

$R$. setigera Brightwell

$R$. shrubsolei Cleve

$R$. stolterfothii $H$, Peragallo

$R$. styliformis Brightwell

Skeletonema costatum (Greville) Cleve

Streptotheca thamensis schrubsole

Striatella unipunctata (Lyngbye) Agardh

Synedra sp

Thalassionema nitzschioides (Grunow) Van Heurck

Thalassiosira sp

$T$. eccentrica Ehrenberg (Cleve)

Thalassiotrix sp

$T$. Grauenfeldi (Grunow) Grunow

$T$. longissima $\mathrm{Cleve}$ and Grunow

$T$. mediterranea Pavillard

$T$. mediterranea Pavillard var. pacifica Cupp

\section{DINOFLAGELADOS}

Ceratium $s p$

C. Gusus (Ehrenberg) Dujardim

C. macroceros Ehrenberg

c. massiliense (Gourret) Jorgensen

C. trichoceros (Ehrenberg) Kofold

C. tripos (0. F. Muller) Nitzsch

Dinophysis sp

D. tripos Gourret

Dissodinium robustum (Kofoid) Matzenauer

Ebria tripartita (Schumann) Lemmermann
Tabela 1. Cont.

GYMNODINIACEAE

Oxytoxum sp

Podolampas sp

Prorocentrum $s p$

P. compressum (0stenfeld) Abë

P. gracile Schiltt

P. micans Ehrenberg

P. rostratum Stein

$P$. triestinum Schlller

protoperidinium sp

$P$. depressum Balley

P. trochoideum (Stein) Lemmermann

SILICOFLAGELADOS

Mesocena polymorpha Lemmermann

COCOLITOFORTDEOS

EUGLENOFICEOS

\section{Aspectos quantitativos}

A Tabela 2 resume a quantidade (em células por m1) de microfitoplanctontes encontrada em cada amostra, e as unidades taxonômicas dominantes (até $10 \%$ do total de células). A Figura 6 representa a variação espacial do total de microfitoplâncton de cada operação.

Existem diferenças qualitativas e quantitativas entre as populações microfitoplanctônicas das três comissões.

Durante PL4, as águas do litoral foram extremamente pobres quantitativamente. Na área próxima a Cabo Frio (estações 1 a 6 ), os valores de abundância não ultrapassaram $10 \mathrm{cel} / \mathrm{ml}$, com populações compostas por Nitzschia delicatissima (est. 1), Thalassiosira sp., Pleurosigma normani, Melosira numuloides e uma pequena diatomácea cêntrica indeterminada (nas estações 1 a 6 ). $\mathrm{Na}$ porção do litoral próxima ao Rio de Janeiro, a quantidade de fitoplâncton aumentou sensivelmente com valores de 10 a $50 \mathrm{cel} / \mathrm{ml}$, em razão sobretudo do desenvolvimento de Thalassiosira sp., que dominou nas estações 6,7 e 8 , e de Skeletonema costatum que dominou nas estações 9 e 10. Nesta ūltima estação, situada na entrada da Baía de Guanabara, Skeletonema costatum atingiu densidades de $270 \mathrm{cel} / \mathrm{ml}$ na superfície e $172 \mathrm{cel} / \mathrm{ml}$ a 5 metros.

Cont. 0 microfitoplâncton coletado durante a operação PL5 revelou-se um pouco mais 
Tabela 2. Variações quantitativas do microfitoplâncton durante as operações PLATAFORMA IV, V e VI e espécies dominantes (em \% do total de células).

Cōdigo das espēcies: Centri (cêntrica indeterminada), Cerati (Ceratum $\mathrm{spp}$ ), Chaeto (Chaetoceros $\mathrm{spp}$ ), Coccon (Cocconeis $\mathrm{sp}$ ), Dinofl (Dinoflagelados), Dipbom (Diploneis bombus), Guifla (Guinardia flaccida), Gymnod (Gymnodiniaceae), Lepdan (Leptocylindrus danicus), Lepmin (L. minimus), Melnum (Melosira nummuloides), Nitzsc (Nitzschia spp), Nitclo (Nitzschia closterium), Nitdel (N. delicatissima), Parsul (Paralia sulcata), Penata (Penata indeterminada), Plenav (Pleurosigma naviculaceum), Plenor ( $P$. normani), Promic (Prorocentrum micans), Protri (Prorocentrum triestinum), Protro (Protoperidinium trochoideum), Rhidel (Rhizosolenia delicatula), Rhifra ( $R$. fragilissima), Rhisto ( $R$. stolterfothi), Skecos (Skeletonema costatum), Thalas (Thalassiossira spp), Thanit (Thalassionema nitzschioides).

Amostra perdida ou de contagem impossivel (-)

\begin{tabular}{|c|c|c|c|c|c|}
\hline Es taçāo & $\begin{array}{l}\text { Profundidade } \\
(\mathrm{m})\end{array}$ & $\begin{array}{c}\text { Abundância } \\
(\mathrm{ce} 1 / \mathrm{m} 1)\end{array}$ & Espëcies dominantes & s $(z)$ & \\
\hline PLATAFORMA & iv & T & & 5 & \\
\hline \multirow[t]{4}{*}{1} & 0 & 7 & Nitdel(79) & & \\
\hline & 5 & 4 & Nitdel (18), Melnum(17), & Thanit (12), & Guifla $(10)$ \\
\hline & 15 & 4 & Nitdel $(24)$, Penata $(18)$, & Lepmin $(16)$, & Lepdan (16) \\
\hline & 30 & 3 & Plenor(24), Centri(19). & Nitclo $(16)$, & Penata (11) \\
\hline \multirow[t]{4}{*}{2} & 0 & 2 & Plenor (41), Melnum (38) & 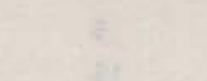 & \\
\hline & 5 & 10 & Thalas $(81)$ & & \\
\hline & 15 & 3 & $\begin{array}{l}\text { Parsul (19), Plenor }(12) \text {, } \\
\text { Nitzsc }(10) \text {, Nitdel }(10)\end{array}$ & Centri $(10)$, & Penata $(10)$, \\
\hline & 30 & 3 & Centri(37), Penata $(20)$, & Nitclo(11) & \\
\hline \multirow[t]{4}{*}{3} & 0 & 5 & Melnum(52), Thanit(11), & Nitdel $(10)$ & \\
\hline & 5 & 1 & Plenor(27), Rhidel(18), & Thanit (18) & \\
\hline & 15 & 3 & Thalas (38), Thanit $(10)$, & Centri $(10)$ & \\
\hline & 30 & 6 & Centri (54), Coccon (24) & & 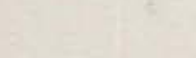 \\
\hline \multirow[t]{4}{*}{4} & 0 & 7 & Centri(52), Nitdel(12) & & \\
\hline & 5 & 6 & Centri $(40)$, Skecos (12) & 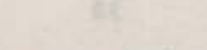 & \\
\hline & 15 & 3 & Thalas $(39)$, Dinof $1(24)$, & Nitclo(11), & Protri(11) \\
\hline & 30 & 2 & Thalas (63), Plenor (11), & Plenav(11) & \\
\hline \multirow[t]{4}{*}{5} & 0 & 1 & Thalas (33), Plenor (13), & Centri(13), & Dinof $1(13)$ \\
\hline & 5 & 3 & Thalas (37), Melnum(13), & Nitdel (13), & Nitclo(11) \\
\hline & 15 & 5 & Thalas ( 83 ) & & \\
\hline & 30 & 7 & Penata $(20)$, Plenor $(18)$, & Dipbom (10) & 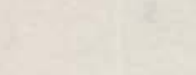 \\
\hline \multirow[t]{4}{*}{6} & $\sqrt{1}$ & 16 & Thal as (72) & a & \\
\hline & 5 & 2 & Thalas (57), Nitdel (13), & Rhis to (13) & \\
\hline & 15 & 2 & Centri (64) & & \\
\hline & 30 & 2 & Penata(32), Lepdan (18), & Skecos (14) & (1) \\
\hline \multirow[t]{4}{*}{7} & 0 & 22 & Thal as ( 82 ) & $x^{2}$ & \\
\hline & etrats & 52 & Euglen (75), Thalas (10) & 56 & \\
\hline & 15 & 13. & Thal as ( 89$)$ & & \\
\hline & 30 & 10 & Thalas $(76)$, Nitdel $(10)$ & & \\
\hline
\end{tabular}


Tabela 2. Cont.

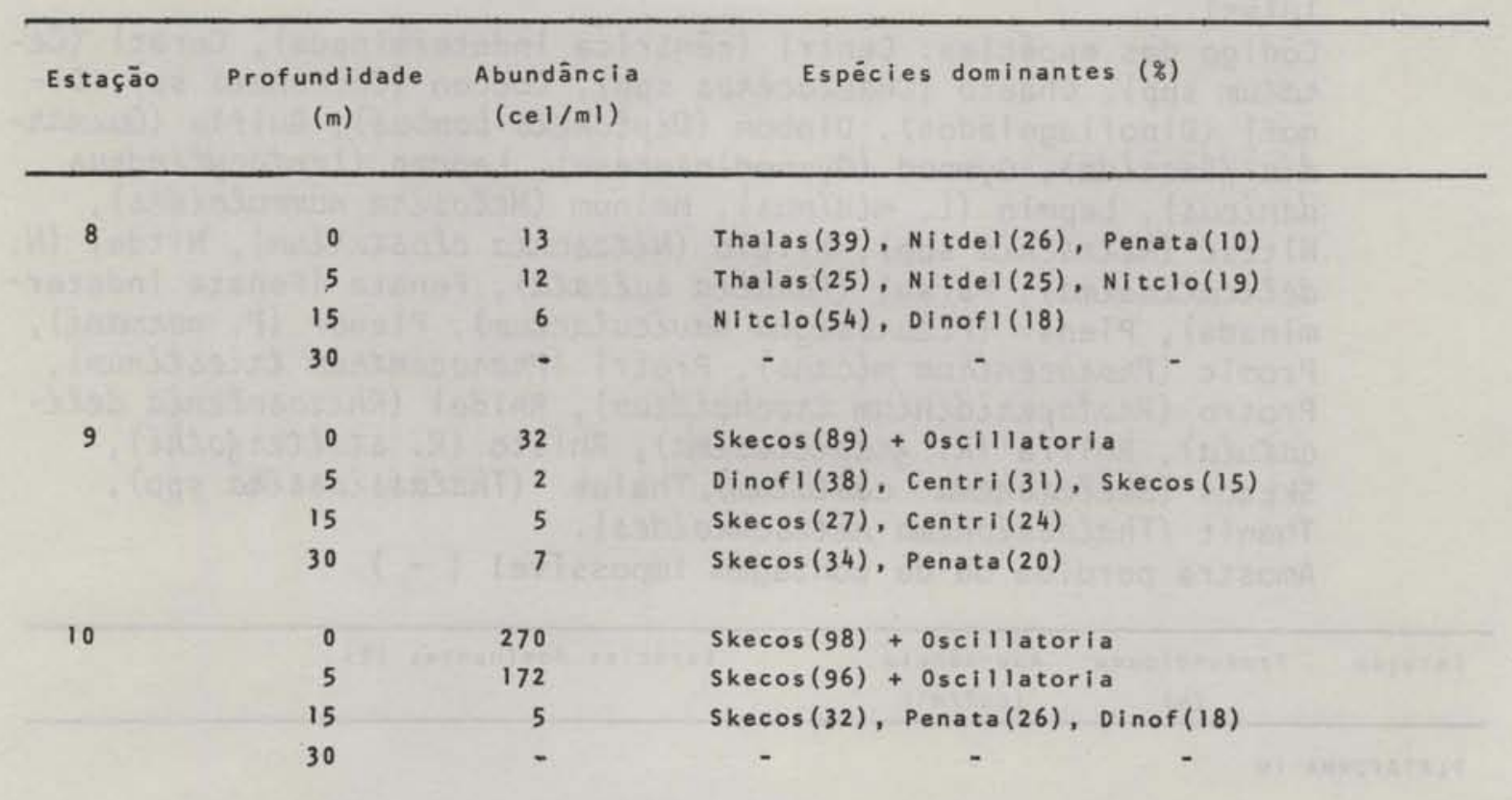

PLATAFORMA V

0

5

15

30

2

3

4

5

6

$\begin{array}{rr}0 & 247 \\ 5 & 20 \\ 15 & 7 \\ 30 & 7\end{array}$

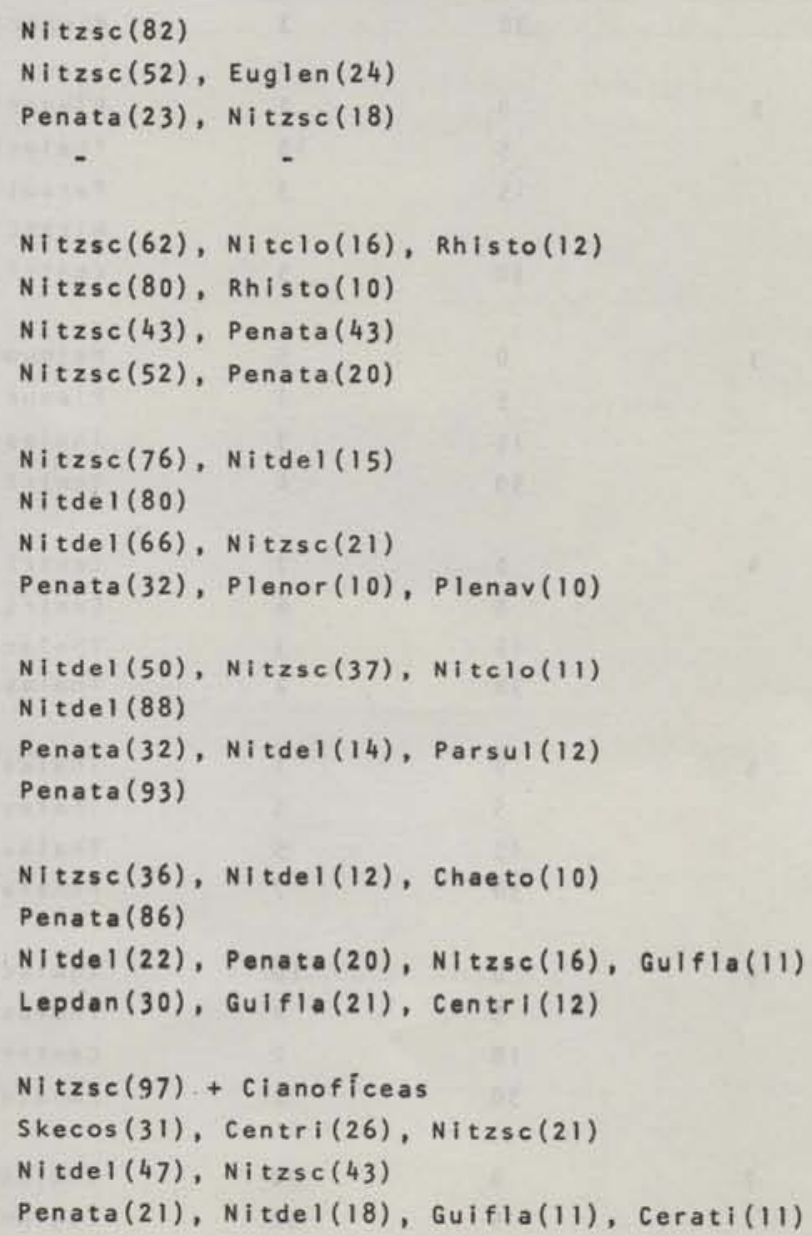


Tabela 2. Cont.

\begin{tabular}{|c|c|c|c|}
\hline Estação & $\begin{array}{l}\text { Profundidade } \\
\text { (m) }\end{array}$ & $\begin{array}{c}\text { Abundâncla } \\
(\text { cel/ml) }\end{array}$ & Espécies dominantes ( $(\xi)$ \\
\hline \multirow[t]{4}{*}{7} & 0 & 179 & Nizzsc(85), Dinofi(11) + Cianoficeas \\
\hline & 5 & 23 & Centri (42), Skecos $(27)+$ Cianoficeas \\
\hline & 15 & 71 & Nitzsc(71), Nitdel (27) \\
\hline & 30 & - & - \\
\hline \multirow[t]{4}{*}{8} & 0 & 61 & Nitzsc(68), Rhifra $(10)$, Dinof $1(10)$ + Cianoficeas \\
\hline & 5 & 6 & Gymnod(28). Nitdel(26), Proto(17), Promic(13) \\
\hline & 15 & 198 & Nitzsc $(74)$, Dinofi $(20)$ + Cianoficeas \\
\hline & 30 & - & - \\
\hline \multirow[t]{4}{*}{9} & 0 & 51 & Gymnod (69), Protro(14) \\
\hline & 5 & 90 & Nitzsc $(87)+C i a n o f i c e a s$ \\
\hline & 15 & 6 & Nitzsc(58), Penata $(19)$ + Detritos \\
\hline & 30 & - & - \\
\hline \multirow[t]{4}{*}{10} & 0 & 21 & Nitzsc(41), Dinof $1(40)+$ oscillatoria \\
\hline & 5 & 49 & Nitzsc(42), Dinofi(32), Skecos(11) \\
\hline & 15 & 98 & Nitzsc $(60)$, Skecos $(19)$, Dinof $1(14)$ \\
\hline & 30 & - & - \\
\hline
\end{tabular}

PLATAFORMA VI

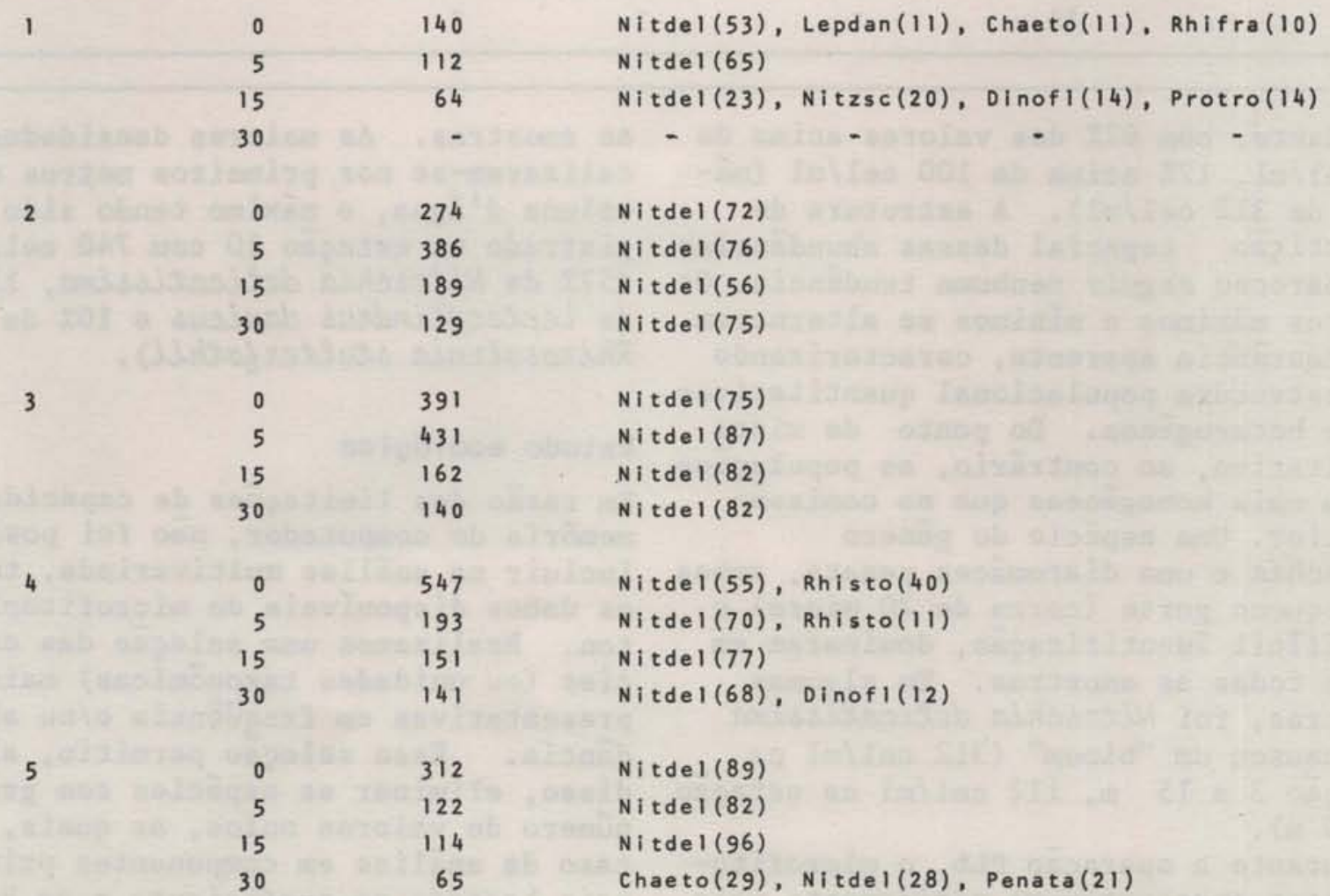


Tabela 2. Cont.

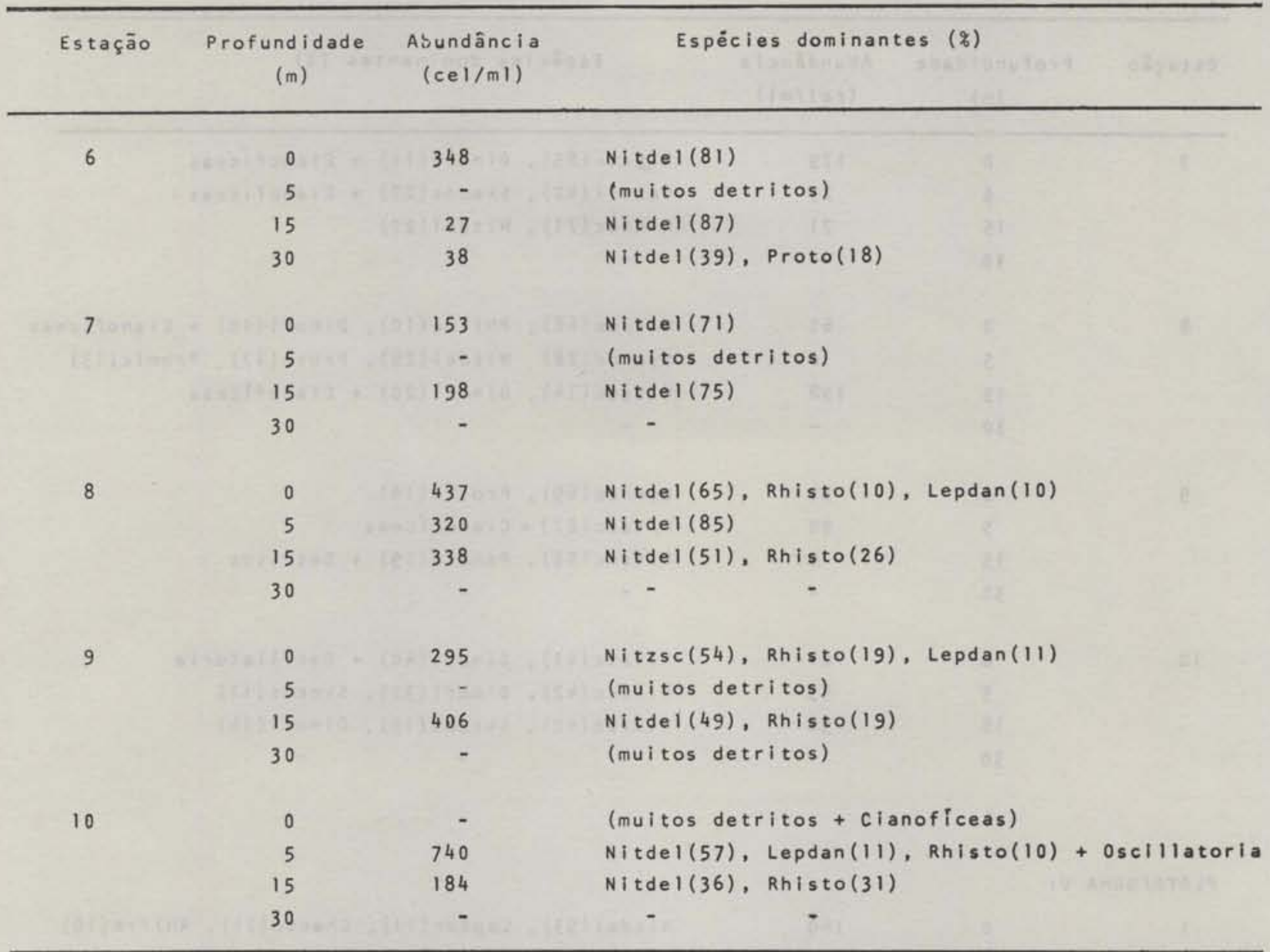

abundante, com $62 \%$ dos valores acima de $10 \mathrm{cel} / \mathrm{ml}, 17 \%$ acima de $100 \mathrm{cel} / \mathrm{ml}$ (máximo de $312 \mathrm{cel} / \mathrm{m} 1$ ). A estrutura de repartição espacial dessas abundâncias não pareceu seguir nenhuma tendência. Os valores máximos e mínimos se alternaram sem coerência aparente, caracterizando uma estrutura populacional quantitativamente heterogênea. Do ponto de vista qualitativo, ao contrário, as populações foram mais homogêneas que na comissão anterior. Uma espécie do gênero

Nitzschia e uma diatomácea penata, ambas de pequeno porte (cerca de $20 \mathrm{micra}$ ) e de dificil identificação, dominaram em quase todas as amostras. Em algumas amostras, foi Nitzschia delicatissima que causou um "bloom" (312 cel/ml na estação 3 a $15 \mathrm{~m}, 112 \mathrm{cel} / \mathrm{ml}$ na estação 4 a $0 \mathrm{~m}$ ).

Durante a operação PL6, o microfitoplâncton apresentou-se nitidamente mais abundante, com $81 \%$ dos valores acima de $100 \mathrm{cel} / \mathrm{ml}$ e $42 \%$ acima de $200 \mathrm{cel} / \mathrm{ml}$.

Nitzschia delicatissima dominou em todas as amostras. As maiores densidades 10calizaram-se nos primeiros metros da coluna d'água, o máximo tendo sido registrado na estação $10 \mathrm{com} 740 \mathrm{cel} / \mathrm{ml}$ (57\% de Nitzschia delicatissima, 11\% de Leptocylindrus danicus e $10 \%$ de Rhizosolenia stolterfothii).

\section{Estudo ecológico}

Em razão das limitações de capacidade de memória do computador, não foi possível incluir na anälise multivariada, todos os dados disponíveis do microfitoplâncton. Realizamos uma seleção das espécies (ou unidades taxonômicas) mais representativas em freqüência e/ou abundância. Essa seleção permitiu, além disso, eliminar as espécies com grande número de valores nulos, as quais, no caso da análise em componentes principais baseada no coeficiente $r$ de Pearson (e conseqüentemente na normalidade dos dados), distorcem fortemente os resultados levando à interpretações errôneas. 

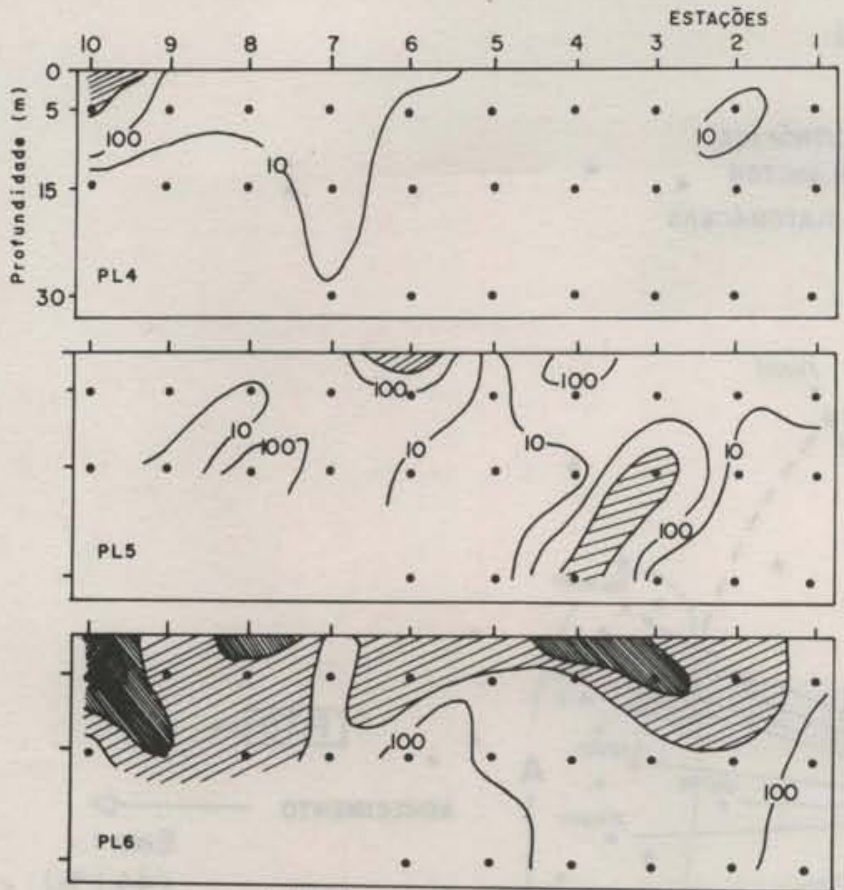

Looende $(\mathrm{cel} / \mathrm{m}$ ) : $600-800$ (100-600 200.400

Fig. 6. Variações quantitativas do microfitoplâncton nas operações PL4, PL5 e PL6.

Mesmo assim, aplicamos uma transformação logarítmica aos dados para corrigir a dissimetria da distribuição.

A Tabela 3 apresenta as 19 variáveis selecionadas para a anālise, com uma indicação de abundância máxima e da freqüência de ocorrência nas amostras.

Os resultados da análise fatorial em componentes principais são representados pela projeção das amostras e dos taxons nos planos fatoriais I-II e II-III

(Figs 7 e 8 ). Nestes planos são também posicionadas as variáveis ambientais

(Tab. 4) que foram introduzidas na aná-

lise como variáveis suplementares para facilitar a interpretaçao dos eixos.

\section{Interpretacão dos fatores}

\section{Eixo I}

0 primeiro componente (eixo I) é provocado pelo grupo de espécies (A) (Fig. 7) compos to de Chaetoceros spp, Hemiaulus sinensis, Thalassiotrix spp, Leptocylindrus danicus, Nitzschia spp, Rhizosolenia fragilissima, $R$. stolterfothii e Eucampia spp, cujas coordenadas no eixo I são fortemente positivas. Esses taxons estão exclusivamente 1 igados às
Tabela 3. Taxons do microfitoplâncton utillizado para a análi se em componentes principais, com indicações de abundância mäxima e percentagem de ocorrência nas amostras de cada operação

\begin{tabular}{|c|c|c|c|c|}
\hline \multirow[b]{2}{*}{ Codiggo } & \multirow{2}{*}{ 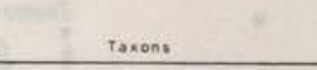 } & \multicolumn{3}{|c|}{ Operaşōes PLATAFORMA } \\
\hline & & iv & v & vi \\
\hline ASTGLA & Asterionetla glacialis & - 32 & - 62 & N. 458 \\
\hline CENTRI & Diatomacea centrica & $\because 87$ & *6 64 & $\cdots 65$ \\
\hline CHAETO & Chaeteceres SpD & - 8 & $\cdot 21$ & $* * 100$ \\
\hline EUCCOR & Eucampia cornuta & 0 & ? & *. 62 \\
\hline GUIFLA & Guinardia blaceida & - 8 & $\ldots 33$ & $\ldots 80$ \\
\hline HERS IN & Hemiaulus sinensis & - 5 & - 6 & $\ldots=100$ \\
\hline LEPDAN & Leptocylendtus danicus & - 18 & $* 49$ & $\cdots * 100$ \\
\hline LEPMIN & Leptocylindrus minimus & - 8 & *. 33 & $\ldots 77$ \\
\hline Nitzsc & Nitzschia spD. & $\cdots 90$ & $\cdots+100$ & $\cdots \cdots *=100$ \\
\hline PENATA & Dlatomacea pennata & *. 87 & $\therefore 94$ & $\ldots 84$ \\
\hline RHIFRA & Rhizosolenia fragiliosiona & . 5 & .. 64 & *.. 94 \\
\hline RHISTO & Rhizesolenia stolcerbothii & $\cdot 13$ & $\because 70$ & $\cdots \times 100$ \\
\hline skecos & Sheletonema costatum & $\cdots \cdots 32$ & $\cdots 39$ & $\cdots 55$ \\
\hline THALAS & Thelassiessire SPP & ... 50 & $\cdot 21$ & $\ldots 45$ \\
\hline THANIT & Thalassionema nitzschiodied & $\because 42$ & $\cdot 33$ & $\cdots 74$ \\
\hline THARIX & Thatausiothrix spp & 0 & $\cdot 12$ & $\cdots 90$ \\
\hline DINOFL & Dinoflagelados indeterm, & $\because 47$ & $\cdots 76$ & $\ldots+87$ \\
\hline PROROC & Prosocentrun spp & * 11 & $\cdots 73$ & $\because 36$ \\
\hline PROTOP & Protoperidinium & 0 & $\approx 36$ & $\cdots 90$ \\
\hline
\end{tabular}

A..... > 10s celulas por Hitro

C..t. de $10^{\circ}$ a $10^{\circ}$

... de $10^{3} \cdot 10^{\circ}$

*. de $10^{2} \cdot 10^{\text {? }}$

* $<10^{x}$

amostras da operação PL 6 , às temperaturas mais elevadas (conseqüentemente às menores concentrações de nutrientes), e são responsáveis pelas maiores quantidades de fitoplâncton e pela saturação das águas em oxigênio dissolvido, com mais de $5,20 \mathrm{ml} / 1$. As variáveis suplementares FITOPK, TEMP e OXIG têm, efetivamente, uma projeção positiva no eixo I, próxima a este grupo de espécies (A). (Tab.4).

Este primeiro fator representa a variabilidade quantitativa global da estrutura populacional do microfitoplâncton em decorrência do aquecimento das águas profundas e do consumo de nutrientes.

\section{Eixo II}

o segundo fator evidenciado pela análise em componentes principais está ligado principalmente a ocorrência das diatomáceas Thalassionema nitzschioides (coeficiente de correlação com o eixo, $r=0,470)$, Thalassiosira spp $(r=0,463)$, 


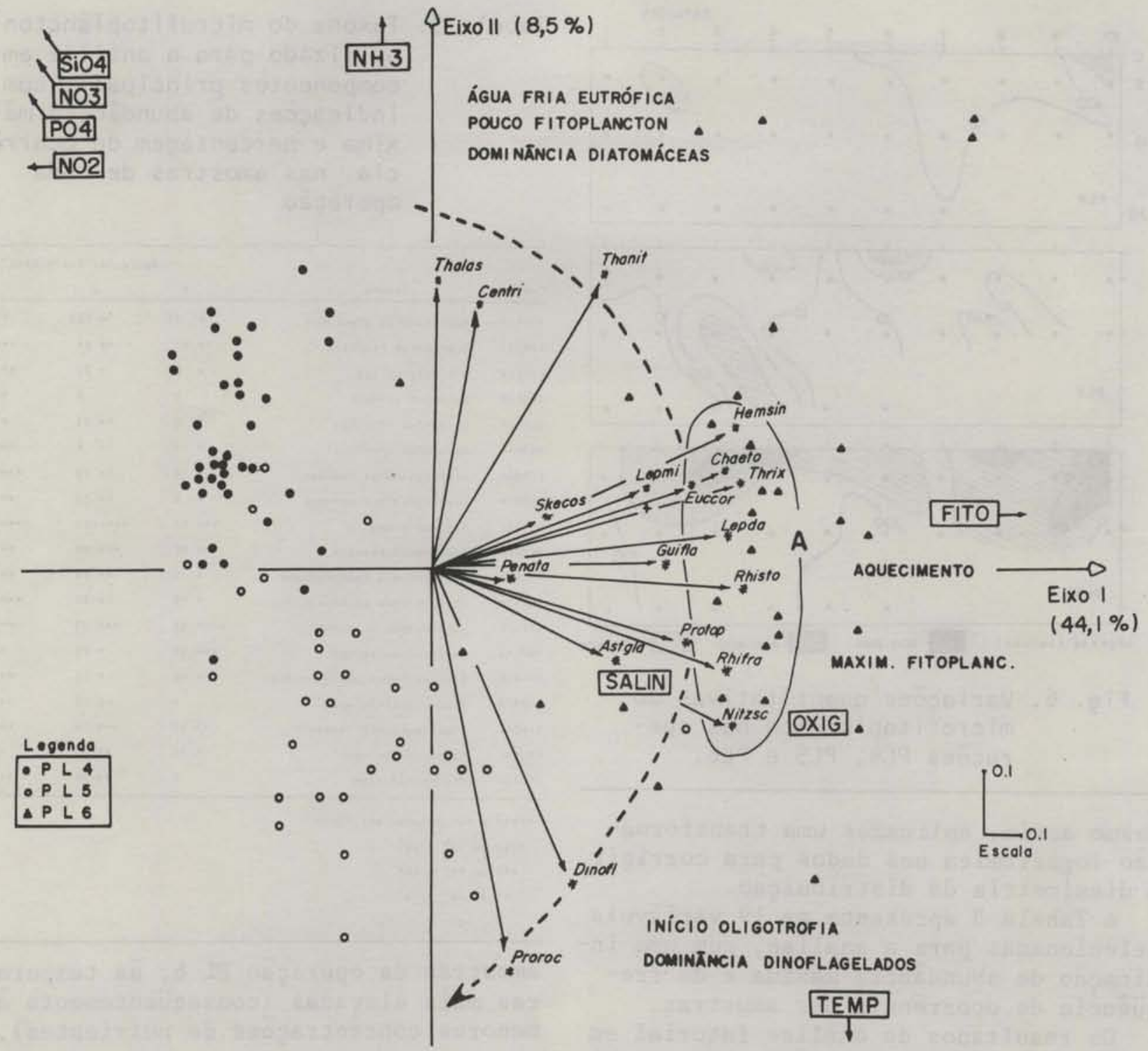

Fig. 7. Plano fatorial $|-|||$ da anälise em componentes principais sobre o microfitoplâncton das operações PL4, PL5 e PL6 (ver significado dos códigos nas Tabelas 3 e 4 ).

e uma cêntrica não identificada $(r=0,402)$, em àguas frias (coordenada de TEMP $=-1,171$ ) e ricas em sais minerais (coordenadas dos nutrientes superiores a 1,00$)$. Essas condições são observadas em quase toda a operação PL 4 e nas águas abaixo da termoclina na operação PL 6 . Com efeito, este eixo separa nitidamente as amostras de PL 4 (lado positivo do eixo) das amostras de PL 5 (lado negativo). Essas amostras apresentam uma abundância algal relativamente baixa (variável FITOPK em posição central no eixo II).

Podemos identificar este segundo com- ponente como um fator qualitativo separando os elementos dominantes na água fria eutrófica, dos elementos encontrados nas águas quentes, acima da termoclina, de característica oligotrófica (maior influência das àguas oceânicas).

Em sintese, o plano I-II configura uma sucessão ecológica, com mudança de população de acordo com o aquecimento das águas, e o grau de evolução do sistema: transição entre o potencial de eutrofia das àguas frias e o início de oligotrofia das águas quentes oceânicas (evolução representada no plano.da Figura 7, pelo tracejado). 


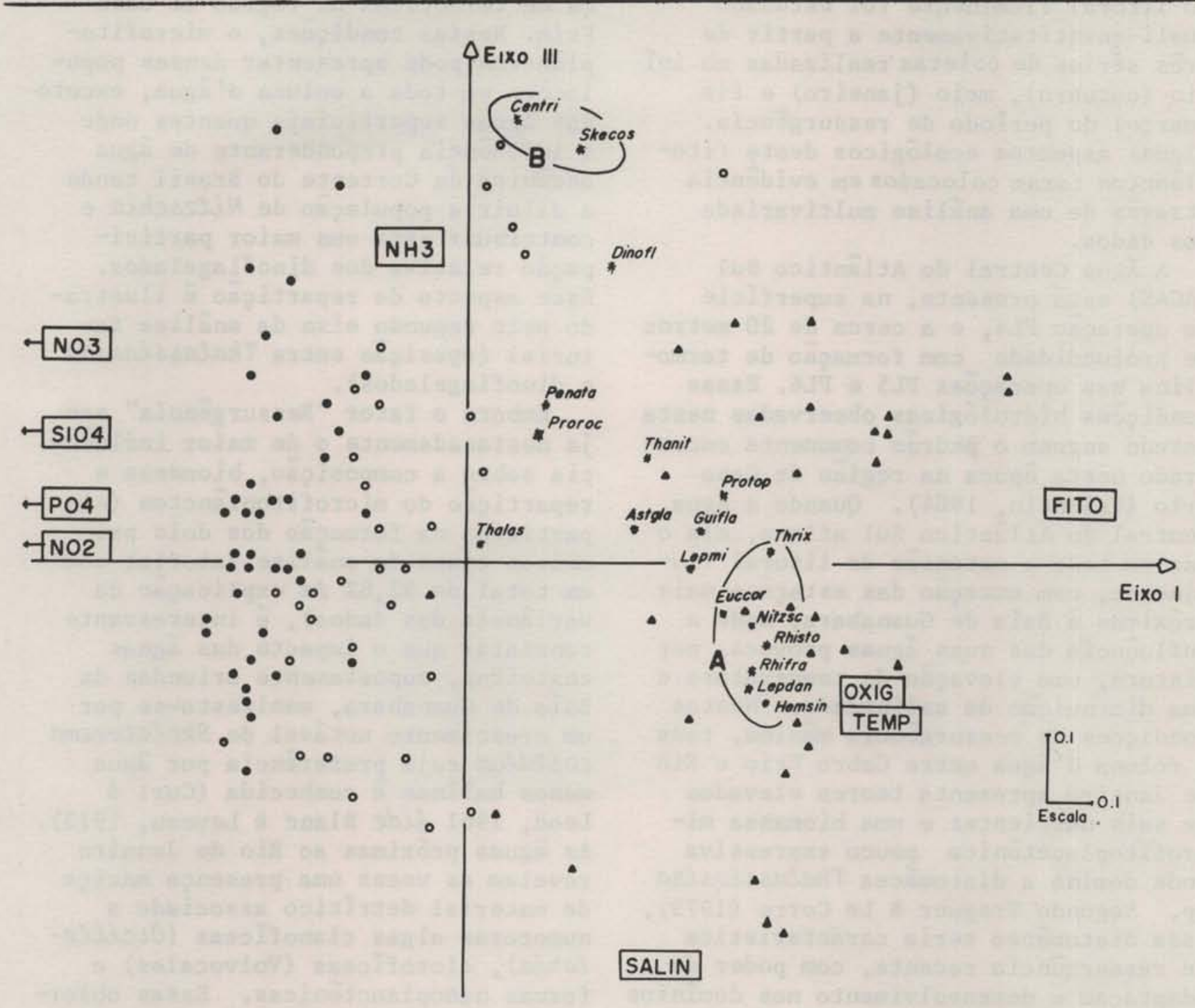

Fig. 8. Plano fatorial $|-||| \mid$ da anälise em componentes principais sobre o microfitoplâncton das operações PL4, PL5 e PL6 (ver significado dos códigos nas Tabelas 3 e 4 ).

Tabela 4. Coordenadas das variáveis ambientais nos três primeiros eixos da anälise em componentes principais

\begin{tabular}{llccc}
\hline & & \multicolumn{3}{c}{ Eixos fatoriais } \\
\multicolumn{2}{c}{ Variáveis } & 1 & 11 & 111 \\
\hline TEM & Temperatura & 1,182 & $-1,171$ & $-0,232$ \\
SALIN & Salinidade & 0,605 & $-0,151$ & $-0,699$ \\
OXIG & Oxigênio & 1,115 & $-0,266$ & $-0,213$ \\
PO. & Fosfato & $-1,237$ & 1,120 & 0,057 \\
NO$_{2}$ & Nitrito & $-1,290$ & 0,658 & 0,008 \\
NO $_{3}$ & Nitrato & $-1,616$ & 1,074 & 0,339 \\
NH. $_{3}$ & Amônia & $-0,138$ & 1,259 & 0,475 \\
SiO. & Silicato & $-1,147$ & 1,273 & 0,196 \\
FITO & Microfitoplâncton & 1,892 & 0,097 & 0,162 \\
\hline
\end{tabular}

\section{Eixo III (Fig. 8)}

Este eixo é marcado pela posição destacada das diatomáceas cêntricas (CENTRI) e Skeletonema costatum (SKECOS) (Grupo B) junto aos teores de amonia $\left(\mathrm{NH}_{3}\right)$ e em oposição à salinidade (SALIN). Não hä duvida que se trata de uma influencia da água costeira (com mistura de água da Baỉa de Guanabara), jā que as amostras das estações 8,9 e 10 têm projeção positiva neste eixo, Do ponto de vista quantitativo, o microfitoplancton sujeito à influência deste terceiro fator alcança fortes valores, com o desenvolvimento de Skeletonema costatum.

\section{Discussão e conclusões}

0 microfitoplâncton das águas costeiras 
do litoral fluminense foi estudado quali-quantitativamente a partir de três séries de coletas realizadas no iní cio (outubro), meio (janeiro) e fim (março) do período de ressurgência. Alguns aspectos ecolögicos deste fitoplâncton foram colocados em evidência através de uma análise multivariada dos dados.

A Ãgua Central do Atlântico Sul (ACAS) está presente, na superfície na operação PL4, e a cerca de 20 metros de profundidade com formação de termoclina nas operações PL5 e PL6, Essas condições hidrológicas observadas neste estudo seguem o padrão comumente encontrado nesta época na região de Cabo Frio (Valentin, 1984). Quando a Āgua Central do Atlântico Sul aflora, ela o faz em toda a extensão do litoral fluminense, com exceção das estações mais próximas à Baía de Guanabara, onde a influência das suas àguas provoca, por mistura, uma elevação da temperatura e uma diminuição da salinidade, Nestas condições de ressurgência máxima, toda a coluna d'água entre Cabro Frio e Rio de Janeiro apresenta teores elevados de sais nutrientes e uma biomassa microfitoplanctônica pouco expressiva onde domina a diatomácea Thalassiosira sp. Segundo Treguer \& Le Corre (1979), essa diatomäcea seria característica de ressurgência recente, com poder de adaptação e desenvolvimento nos dominios bentônicos e pelágicos (espécie tichopelágica), o que the permitiria constie tuir populações densas nas águas superficiais após terem sido arrastadas do sedimento por correntes de ressurgência, Margalef (1978), no seu modelo de sucessão fitoplanctônica em função da turbulência e da fertilidade das àguas, coloca efetivamente Thalassiosira como espécie das mais favorecidas por esses dois fatores.

Quando a ressurgēncia não é total, ou quando ocorre um aquecimento superficial em consequência do enfraquecimento dos ventos de NE, a isoterma de 18 graus (temperatura limite das ACAS) posiciona-se entre 15 e 30 metros de profundidade; - sistema pelägico é estratificado e as condições tornam-se favoráveis ao desenvolvimento de pequenas diatomáceas do gênero Nitzschia, ou penatas de difícil identificação, Valentin et al. (1985) já mostraram a relação entre essas pequenas diatomáceas e a presen- ça de termoclina na região de Cabo Frio. Nestas condições, o microfitoplâncton pode apresentar densas popur lações em toda a coluna d'água, exceto nas águas superficiais quentes onde a influência preponderante de água oceânica da Corrente do Brasil tende a diluir a população de Nitzschia e contribuir para uma maior participação relativa dos dinoflagelados. Este aspecto da repartição é ilustrado pelo segundo eixo da análise fatorial (oposição entre Thalassiosira e dinoflagelados).

Embora o fator "Ressurgência" seja destacadamente o de maior influência sobre a composição, biomassa e repartição do microfitoplâncton (ele participa na formação dos dois primeiros eixos da análise fatorial com um total de $52,6 \%$ de explicação da variância dos dados), é interessante constatar que o impacto das águas costeiras, supostamente oriundas da Baỉa de Guanabara, manifesta-se por um crescimento notável de Skeletonema costatum cuja preferência por āgua menos halinas è conhecida (Curl \& Leod, 1961 fide Blanc \& Leveau, 1973). As äguas próximas ao Rio de Janeiro revelam as vezes uma presença maciça de material detrítico associado a numerosas algas cianofíceas (Oscillatoria), clorofíceas (Volvocales) e formas nanoplanctônicas. Essas observações confirmam a influência da descarga da Baía de Guanabara, onde essas algas proliferam (Sevrin-Reyssac et al., 1979), sobre a estrutura do sistema planctônico das águas do litoral fluminense, Essa influência é mais marcada quando existe uma estratificação térmica da coluna d'água, o que certamente facilita o escoamento das águas continentais em direção a Cabo Frio sob condições de ventos e marés favorāveis.

Em resumo, o fator principal da variação do microfitoplâncton das águas costeiras fluminenses é a estrutura hidrológica (presença de termoclina na camada eufótica, homotermia "fria" após afloramento das águas profundas, escoamento das águas da Baía de Guanabara). Qualquer estudo sobre a dinâmica do potencial biológico da região deverâ levar em conta a estrutura térmica da coluna d'água, E de se esperar que uma maior 
riqueza biológica ocorra em situação de pós-afloramento, quando, em consequêencia de aquecimento superficial ou inversão dos ventos, a estratificação térmica assim formada, facilita uma eutroficação de dupla origem, da ressurgência e da Baía de Guanabara, e contribui para uma maior concentração planctônica na camada de mistura.

\section{Resumo}

0 microfitoplâncton das águas costeiras entre Cabo Frio e Rio de Janeiro foi coletado durante as operações PLATAFORMA IV, $\mathrm{V}$ e VI do AvPqOc SO OLIVEIRA (DGN) nos meses de outubro de 1984 e janeiro e março de 1985. As variações qualitativas e quantitativas foram análisadas em função das condições hidrológicas por meio de um tratamento estatístico multivariado dos dados. 0 fenomeno de ressurgência, responsāvel seja pelo afloramento da Àgua Central do Atlântico Sul, seja pela formação de uma termoclina na camada eufótica, é o fator determinante do crescimento algal que começa com espécies de pequeno porte (Skeletonema costatum, Nitzschia spp) e evolui para uma maior diversidade com espécies dos gêneros Guinardia, Rhizosolenia, Chaetoceros, Thalassiothrix, Em condição de estratificação da coluna d'água notou-se a influência das águas da Baỉa de Guanabara, com forte crescimento de Skeletonema costatum, e uma grande quantidade de detritos associados a algas cianoficeas e formas nanoplanctônicas.

\section{Agradecimentos}

Estudo realizado com ajuda financeira da Comissão Interministerial

para os Recursos do Mar (Sub-Projeto CIRM, no 9.226) e do Conselho Nacional de Pesquisas Científicas e Tecnológicas (CNPq, bolsa n? 300085/83 Oc, para o segundo autor).

Agradecemos ao Comandante e à tripulação do AvPqOc SO OLIVEIRA, ao biólogo José Ribamar Santos Silva pela sua ajuda na coleta das amostras de plâncton, e à equipe da seção de Química do IEAPM pelas coletas e anālises das amostras de química,

\section{Referências bibliográficas}

ANDRE, D. L.; JACOB, S. A. \& VALENTIN, J. L. (no prelo) Características hidrológicas da região costeira entre Cabo Frio e Rio de Janeiro (resultados de quatro operações oceanográficas). Anais hidrogr., Rio de Janeiro.

BLANC, F. \& LEVEAU, M. 1973. Plancton et eutrophie: aire d'épandage rhodanienne et Golfe de Fos. Thése Doct. Sci. Nat. Univ. Aix Marseille II. 681p.

CLEVE-EULER, A. 1951. Die diatomeen von Schweden und Finnland. K. svenska VetenskAkad. Handl., ser. 4, 2(1):1128.

\section{Die diatomeen}

von Schweden und Finnland. $K$. svenska VetenskAkad. Hand1., ser. 4, 3(3):1130.

\section{Die diatomeen} von Schweden und Finnland. K. svenska VetenskAkad. Hand1., ser. 4, 4(1):1$134 ; 4(5): 1-221$.

\section{Die diatomeen}

von Schweden und Finnland. $K$. svenska VetenskAkad. Hand1., ser.4, 5(4):1198.

CUPP, E. E. 1943. Marine plankton diatoms of the west coast of North America. Bull. Scripps Instn Oceanogr. tech. Ser., 5(1):1-237.

HARMANN, H. H. 1970. Modern factor analysis. Chicago, University of Chicago Press. $474 \mathrm{p}$.

HENDEY, N. I. 1964. An introductory account of the smaller algae of British coastal waters. Part V. Bacillariophyceae (diatoms). Fishery Invest., Lond., ser. 4.

JACOBI, C. M. 1987. Spatial and temporal distribution of Amphipoda associated with mussel beds from the Bay of Santos (Brazil). Mar. Ecol. -Prog. Ser., 35:51-58. 
MARGALEF, R. 1978. Les types

biologiques du phytoplankton considérés comme des alternatives de survie dans un milieu instable. Oceanologica Acta, 1(4):493-509.

PERAGallo, H. \& PERAGALlO, M. 1965. Diatomées marines de France et des districts maritimes voisins. Grez-sur-Loing, M. J. Tempère. 2v.

SEVRIN-REYSSAC, J.; MACHADO, M. C.; MOTTA SCHUTZE, M. L.; GASPAR RIBAS, S.; COSTA DE LIMA, I.; ARAUJO LIMA, C. \& ESTEVES, C. P. 1979. Biomasse et production du phytoplancton de la baie de Guanabara (Etat de Rio de Janeiro), Brésil et du secteur océanique adjacent. Variations de mai à juillet 1978. Bull. Mus. natn. Hist. nat., Paris, 4ㅌ sér., 1:329354.

STEIDINGER, K. A. \& WILLIAMS, J. 1970. Dinoflagellates. Mem. Hourglass Cruises, Mar. Res. Lab., Fla Dep. nat. Res., 2:1-252.

TREGUER, P. \& LE CORRE, P. 1979. The ratios of nitrate and silicate during uptake and regeneration phases of the Maroccan upwelling regime. Deep-Sea Res., 26A:163-184.

UTERMOHL, H. 1958. Zur Vervolkommung der quantitative phytoplankton-methodik. Mitt. int. Verein. theor. angew. Limno1., 9:1-38.
VALENTIN, J. L. 1981. L'ècosystème d'upwelling à Cabo Frio (Brésil). Analyse en composantes principales du plancton à une station fixe. Oceanologica Acta, 3(1):43-50.

paramètres hydrobiologiques dans $1 \mathrm{a}$ remontée de Cabo Frio (Brésil). Mar. Biol., 82:259-276.

; LINS DA SILVA, N. M. \& BASTOS, C. T. B. T. 1985. Les diatomées dans $1^{\prime}$ upwelling de Cabo Frio (Brésil): liste d'espèces et étude écologique. J. Plankt. Res., 7(3): 313-337.

; MONTEIRO-RIBAS, W. M. \&

MUREB, M. A. 1987. O zooplancton das águas superficiais costeiras do litoral fluminense: análise multivariada. Ciênc. Cult., S Paulo, 39(3): 265-271.

VERDINELLI, M. A. 1980. Análise inercial em ecologia. Estudo na plataforma continental argentina (região sul de Buenos Aires) das populaçoes de Copepoda planctônicos e considerações sobre Cladocera e Copelata. Tese de doutorado. Universidade de São Paulo, Instituto Oceanogräfico. 162p.

(Recebido em 19-12-86; acei to em 10-06-88) 